\title{
The Assessment of Platelet Indices Levels in Patients with Generalized Anxiety Disorder
}

\author{
Farzana Yeasmin Mukta1*, Qazi Shamima Akhter ${ }^{2}$, Afrina Binte Azad ${ }^{3}$, Khusbun Nahar Layla ${ }^{4}$, \\ Tahmina Akter5, Kazi Lutfar Rahman6, Sudipta Sarker ${ }^{7}$
}

\author{
${ }^{1}$ Kurmitola General Hospital, Dhaka, Bangladesh \\ ${ }^{2}$ Department of Physiology, Dhaka Medical College and Hospital, Dhaka, Bangladesh \\ ${ }^{3}$ National Institute of Traumatology and Orthopaedics Rehabilitation, Dhaka, Bangladesh \\ ${ }^{4}$ Ibrahim Medical College, Dhaka, Bangladesh \\ ${ }^{5}$ Department of Physiology, Dhaka Medical College, Dhaka, Bangladesh \\ ${ }^{6}$ Rt-PCR Lab, Kurmitola General Hospital, Dhaka, Bangladesh \\ ${ }^{7}$ Charbaria Union Health and Family Welfare Centre, Barishal Sadar, Barishal, Bangladesh \\ Email: ^farzanayeasminmukta@gmail.com, shamimaqazi@yahoo.com, afrina04emc@gmail.com, laylaluna7671@gmail.com, \\ tahmina.runa.akter1@gmail.com,klrahman@yahoo.com, sarkersudipta1234@gmail.com
}

How to cite this paper: Mukta, F.Y., Akhter, Q.S., Azad, A.B., Layla, K.N., Akter, T., Rahman, K.L. and Sarker, S. (2021) The Assessment of Platelet Indices Levels in Patients with Generalized Anxiety Disorder. Journal of Biosciences and Medicines, 9, 116-124. https://doi.org/10.4236/jbm.2021.99010

Received: July 28, 2021

Accepted: September 11, 2021

Published: September 14, 2021

Copyright $\odot 2021$ by author(s) and Scientific Research Publishing Inc. This work is licensed under the Creative Commons Attribution International License (CC BY 4.0).

http://creativecommons.org/licenses/by/4.0/

\begin{abstract}
Background: The prevalence of anxiety disorders is increasing in the world. Studies revealed that generalized anxiety disorder may lead to change in platelet size, volume and functions. Thus, the changes in platelet indices may increase the future risk of thrombotic diseases in patients with Generalized Anxiety Disorder (GAD). Aim: To evaluate platelet indices (total count of platelet, mean platelet volume, platelet distribution width, plateletcrit) levels in patients with generalized anxiety disorder. Material and Methods: A cross-sectional study was performed in the Department of Physiology, Dhaka Medical College, Dhaka from July 2019 to June 2020. After obtaining ethical clearance, a total of 144 individuals were selected based on inclusion and exclusion criteria with ages ranging from 18 - 50 years. Group A was the study group selected from Out Patient Department of Psychiatry of Dhaka Medical College Hospital, Dhaka, diagnosed by an experienced psychiatrist. Group B was the control group who were apparently healthy adults selected from different areas of Dhaka city. The subjects were interviewed and detailed history regarding personal, family, medical and drug history were taken. Prior to sample collection, informed written consent was taken from the participants. Platelet indices (total count of platelet, mean platelet volume, platelet distribution width, plateletcrit) were measured in the Department of Laboratory Medicine, Dhaka Medical College Hospital, Dhaka. Statistical Analysis: For statistical analysis, the Unpaired Student's "t" test was considered using SPSS 25.0 version. Results: Mean platelet volume of generalized anxiety disorder patients was
\end{abstract}


significantly higher $(p<0.001)$ than the control group. Platelet distribution width and plateletcrit were higher in the study group than the control group. Conclusion: It can be concluded that generalized anxiety disorder patients may have more chance of thrombotic diseases due to significantly higher mean platelet volume and higher platelet distribution width, plateletcrit than healthy adults.

\section{Keywords}

GAD, Platelet Indices, Healthy Adults

\section{Introduction}

Mental disorders are a major public health problem in the world. Mental disorders are increasing in the developed countries and the prevalence rate is about $50 \%$. Among mental disorders, the prevalence of anxiety disorder is common [1]. The prevalence of mental disorders is also high in Bangladesh. So, psychiatric morbidity is a significant public health problem in Bangladesh [2]. Anxiety increases platelet activity and may play an important role in cardiovascular diseases such as myocardial infarction, ischemic heart diseases, congestive heart failure, coronary artery disease, unstable angina, etc [3].

Generalized Anxiety Disorder (GAD) is characterized by persistent and chronic worry that lasts for at least 6 months [4]. It can occur during stressful life circumstances such as family, financial, health, exam, future related problems, etc. It has a harmful effect on health. It aggravates physical diseases especially cardiovascular and cerebrovascular diseases [5].

Platelets are key components of hemostasis. Platelets can quickly adhere and aggregate at the sites of vascular injury. Thus, they form the platelet plug [6]. Platelets can be used as important tools in various psychiatric research. Platelets contain many clotting and growth factors, as well as, serotonin (5-HT), ADP, ATP and calcium at high concentrations. They have $\alpha-2, \beta-2$ adrenaline receptors, benzodiazepine receptors and 5-HT receptors on their membrane similar to neurons. So, they can reflect the biochemical changes of the central nervous system [7].

Platelet indices such as total count of platelet, Mean Platelet Volume (MPV), Platelet Distribution Width (PDW) and plateletcrit are the important biomarkers of platelet activation [8]. Platelets with higher mean platelet volume are metabolically and enzymatically more active with increased thrombotic potential [9]. Large platelets aggregate more rapidly than the smaller platelets as they contain a higher level of thromboxane $\mathrm{A}_{2}$ and procoagulant factors like P-selectin, Glycoprotein-IIb/IIIa, etc [10].

Altered platelet indices act as a risk factor for arterial thrombotic events like myocardial infarction, cerebrovascular thromboembolism transient ischemic attacks, etc [11]. Some studies have shown altered platelet indices levels in anxiety 
disorder in different populations. In Turkey, a study among 61 generalized anxiety disorder patients reveals that mean platelet volume and platelet distribution width are significantly higher than healthy subjects [12]. Another study among 60 generalized anxiety disorder patients also reveals that mean platelet volume values are significantly increased in generalized anxiety disorder patients than healthy controls [13].

Stressful life and anxiety elevate blood catecholamine levels which are potent stimuli for platelet activation. Increased sympathetic activity causes excess secretion of catecholamines that can stimulate platelets via $\alpha$-2 adrenoceptors. Then the shape of platelets is changed from discoid to spherical and means platelet volume values are also changed. Active platelets may cause thrombosis and increase the risk of cardiovascular diseases [14]. Vizioli et al. (2009) also performed a study and found that anxiety and stress cause increased sympathetic activity and thus cause higher mean platelet volume values. Thus, anxiety may increase the future risk of thrombotic diseases [15]. So, this study was conducted to assess platelet indices levels in generalized anxiety disorder patients and bring more awareness to prevent thrombotic disease-related morbidity.

\section{Material and Methods}

This prospective type of analytical cross-sectional study was carried out the Department of Physiology, Dhaka Medical College Hospital, Dhaka, from July 2019 to June 2020. A total of 144 subjects, among them 72 newly diagnosed generalized anxiety disorder patients without previous history of drug intake by an experienced psychiatrist and 72 healthy individuals, aged ranging from $18-50$ years were selected for this study.

1) Study Design: Prospective type of analytical cross-sectional study.

2) Study Location: Department of Physiology, Dhaka Medical College and Hospital, Dhaka.

3) Study Duration: July 2019 to June 2020.

4) Sample Size Calculation: The sample size was estimated on the basis of the prevalence rate of generalized anxiety disorder from previous study. We assumed that the level of significance was $5 \%$. The sample size actually obtained for this study was 72 subjects for each group.

5) Sample Size: 72 subjects in each group.

6) Subjects \& Selection Method: Total 144 subjects divided into two groups.

a) Group A (study group) consisted of 72 newly diagnosed generalized anxiety disorder patients diagnosed according to the fifth edition of the Diagnostic and Statistical Manual of Mental Disorders (DSM-5) by an experienced psychiatrist. These patients had no previous history of anti-psychotic drug intake.

b) Group B (control group) consisted of 72 healthy individuals.

7) Inclusion Criteria

- Age: 18 - 50 years.

- Gender: Male and female. 
- BMI: 18 - $24.9\left(\mathrm{~kg} / \mathrm{m}^{2}\right)$.

- Ethnicity: Bengali.

\section{8) Exclusion Criteria}

- History of thromboembolic events, hypertension, diabetes mellitus, hyperlipidemia, liver disease, malignancy.

- History of alcohol and substance use.

- Pregnancy and lactation.

- History of taking anticoagulant drug.

- Smoker.

- History of taking antipsychotic drug.

- History of comorbid psychiatric illness like unipolar major depressive disorder, schizophrenia, etc.

\section{9) Procedure Methodology}

After selection of the subjects, the nature, purpose and benefit of the study were explained to each subject in details. They were encouraged for voluntary participation. They were allowed to withdraw from the study whenever they feel like. Informed written consent was taken from the participants. The research work was carried out after obtaining ethical clearance from concerned departments, Research Review Committee and Ethical Review Committee of Dhaka Medical College, Dhaka. Study subjects and controls who were interested to take part in the study were requested to attend the Department of Physiology, Dhaka Medical College, Dhaka. Before taking blood, detailed personal, family, drug and medical history were taken. Anthropometric measurement of the study subjects and controls was done and blood pressure was measured. All the information's were recorded in a prefixed data collection form. Then both study subjects and controls were brought to the Department of Laboratory Medicine, Dhaka Medical College Hospital, Dhaka. Platelet indices (total count of platelet, mean platelet volume, platelet distribution width, plateletcrit) were estimated in the Department of Laboratory Medicine, Dhaka Medical College Hospital, Dhaka, by using Penta Dx Nexus Automated Haematology Analyzer machine. Subjects who are unable to come to Dhaka Medical College, their blood samples were carried in a cool box to the respective department of Dhaka Medical College Hospital, Dhaka for investigations.

\section{0) Statistical Analysis}

All the parameters were expressed as mean \pm SD (standard deviation). Unpaired Student's “ $t$ " test was performed to compare between two groups. The $p$ value $<0.05$ was accepted as level of significance. Statistical analyses were performed by using a computer based statistical program SPSS (Statistical package for social science) version 25.0.

\section{Results and Discussions}

In the current study, Table 1 and Figure 1 show that the mean total count of platelet of both groups was within normal range but lower than the control group which was not statistically significant. Similarly, Almis and Aksoy (2018) 
Table 1. Platelet indices (total count of platelet, mean platelet volume, platelet distribution width and plateletcrit) in both groups $(\mathrm{N}=144)$.

\begin{tabular}{cccc}
\hline Parameters & $\begin{array}{c}\text { Group A } \\
\left(\mathrm{n}_{1}=72\right)\end{array}$ & $\begin{array}{c}\text { Group B } \\
\left(\mathrm{n}_{2}=72\right)\end{array}$ & $\boldsymbol{p}$ Value \\
\hline Total count of platelet $\left(\times 10^{3} / \mu \mathrm{l}\right)$ & $286.7 \pm 55.3$ & $299.9 \pm 41.5$ & 0.109 \\
Mean platelet volume (fl) & $10.68 \pm 0.68$ & $7.51 \pm 0.40$ & $<0.001^{*}$ \\
Platelet distribution width (\%) & $14.60 \pm 1.51$ & $14.00 \pm 1.41$ & 0.412 \\
Plateletcrit (\%) & $0.16 \pm 0.03$ & $0.15 \pm 0.03$ & 0.083 \\
\hline
\end{tabular}

Data were expressed as mean $\pm \mathrm{SD}$. Unpaired Student's " $\mathrm{t}$ " test was performed to compare between two groups. ${ }^{*}$ significant; $\mathrm{N}$ : Total number of subjects; $\mathrm{n}_{1}$ : Number of subjects in group $\mathrm{A} ; \mathrm{n}_{2}$ : Number of subjects in group B; Group A (Study group): Generalized Anxiety Patients; Group B (Control group): Healthy Subjects.

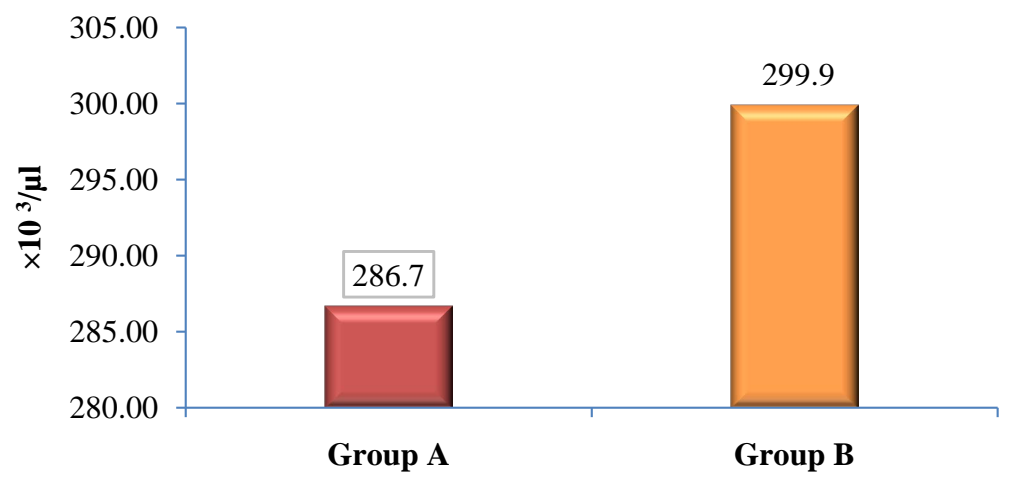

Mean total count of platelet

Figure 1. Mean total count of platelet $\left(\times 10^{3} / \mu \mathrm{l}\right)$ of the study subjects in both groups $(\mathrm{N}=$ 144). N: Total number of subjects; Group A: Generalized anxiety disorder patients; Group B: Healthy subjects.

found lower platelet count in patients with generalized anxiety disorder than healthy controls which was not statistically significant [13]. Asoglu et al. (2016), Bondade et al. (2018), Borgohain and Boro (2020) also found lower platelet count in panic disorder than healthy control which was not statistically significant. This finding was due to non-linear inverse relation between platelet volume and platelet count [16] [17] [18].

On the contrary, Gul et al. (2014) found higher platelet count in panic disorder than healthy control which was not statistically significant [19]. Ransing et al. (2016), Kokacya et al. (2015) also found higher platelet count in panic disorder than healthy control which was not statistically significant. This disagreement was due to various method of estimation of total count of platelet [12] [20].

Table 1 and Figure 2 show that the mean of Mean Platelet Volume (MPV) was higher in study group than control group which was statistically significant $(p<0.001)$. Similar type of observations was found by different researchers. Some postulated mechanisms are suggested by various researchers of different countries which may imply the possible mechanism regarding the changes in the present study. Platelets contain $\alpha-2, \beta-2,5-\mathrm{HT}$ receptors similar to central nervous 


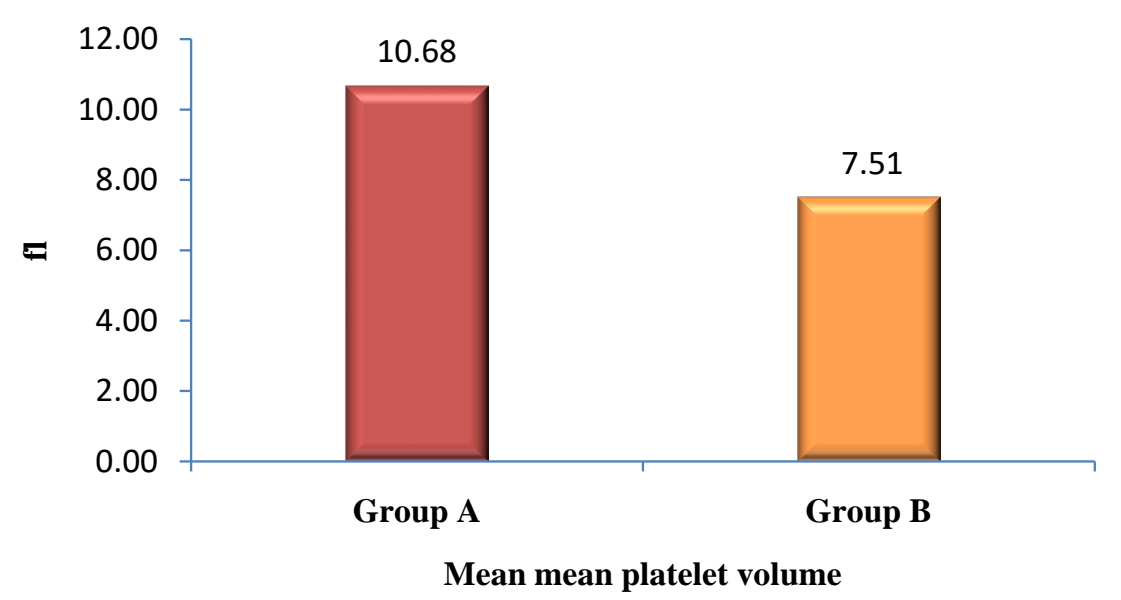

Figure 2. Mean of Mean Platelet Volume (MPV) of the subjects in both groups $(\mathrm{N}=$ 144). N: Total number of subjects; Group A: Generalized anxiety disorder patients; Group B: Healthy subjects.

system. Emotional stress and anxiety may stimulate sympathetic activity and increase blood catecholamine levels. This elevated catecholamine levels cause platelet activation via $\alpha-2$ receptors. So, platelet activation occurred. Activated platelets then release factors that promote platelet aggregation [12] [13]. Active platelets may increase the risk of thrombosis like myocardial infarction, transient ischemic attacks, etc [14] [15]. Another mechanism describes the role of serotonin in platelet activation. Platelet and serotonergic neurons use the same serotonin transporter to transport serotonin into their cells. Moreover, serotonin levels in the cerebrospinal fluid and platelets are strongly correlated. In case of increased stress and anxiety, serotonin binds with 5-HT-2 receptors on platelets. Thus, mediates the release of factors that cause platelet aggregation. When platelets become more aggregated total count of platelet decreases and stimulate pluripotent hematopoietic stem cells to produce more megakaryocytes. During activation, platelet size increases and platelet become more active than small platelets. So, average size of platelet (mean platelet volume) increases in generalized anxiety disorder [13] [16]. Asoglu et al. (2016), Bondade et al. (2018), Borgohain and Boro (2020) also found that mean platelet volume levels are significantly higher in anxiety disorder patients group than control group [16] [17] [18].

On the other hand, Gul et al. (2014) showed that mean platelet volume of panic disorder patients was significantly lower than healthy controls. Ransing et al. (2017) also found lower mean platelet volume in panic disorder patients than healthy controls. This disagreement in findings might have occurred due to abnormalities of 5-HT receptor functioning. So, platelet 5-HT (serotonin) uptake and platelet activity decreased. This abnormal function of platelet may be due to different variations in genetic composition of different population. Thus, mean platelet volume was lower in panic disorder [19] [20].

In the current study, Table 1 and Figure 3 also show that mean platelet distribution width of both the study subjects and healthy individuals were within 


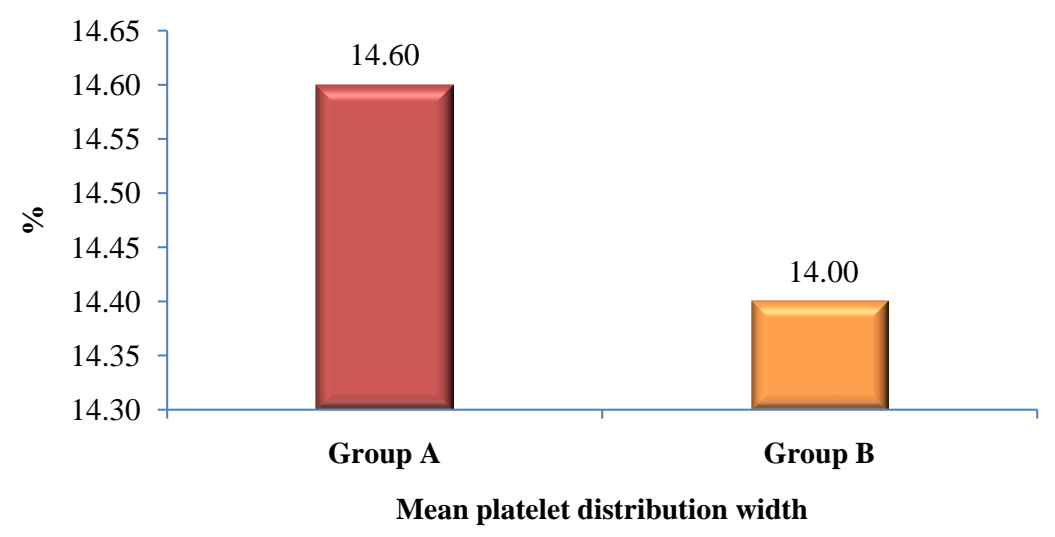

Figure 3. Mean platelet distribution width (\%) of the subjects in both groups $(\mathrm{N}=144)$. N: Total number of subjects; Group A: Generalized anxiety disorder patients; Group B: Healthy subjects.

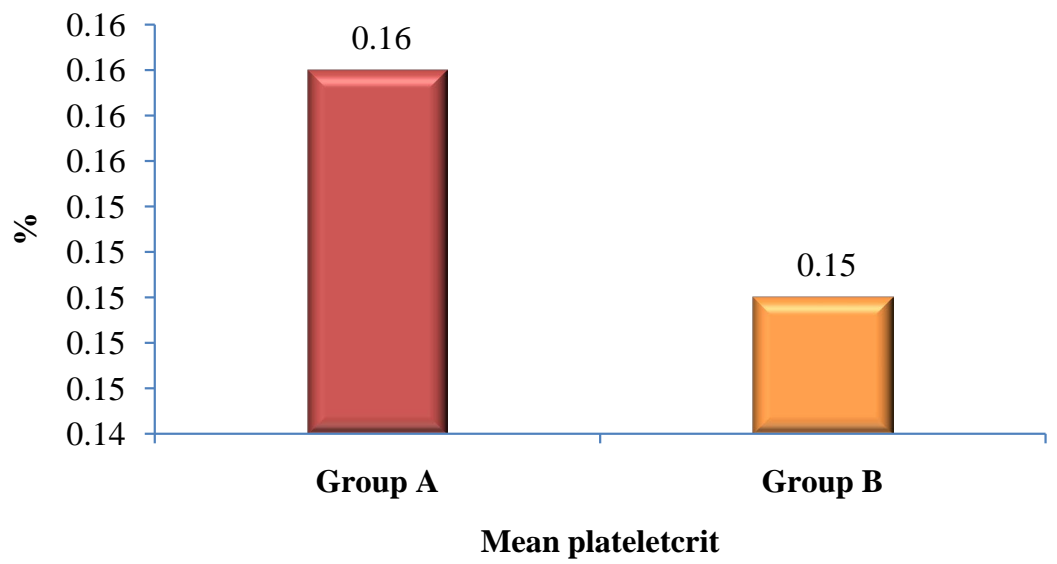

Figure 4. Mean plateletcrit (\%) of the subjects in both groups $(\mathrm{N}=144)$. N: Total number of subjects; Group A: Generalized anxiety disorder patients; Group B: Healthy subjects.

normal range but mean platelet distribution width of study subjects was higher than control group. The mean differences between the groups were not statistically significant. In generalized anxiety disorder mean platelet volume increases and platelet become more active. So, more platelet aggregation occurred. Then platelet changes their own characteristics. They begin to swell and form pseudopods protruding from their surface. Thus, platelet becomes more variable in volume, size (platelet distribution width) and more reactive than normal [13]. Similar type of observations was found by Almis and Aksoy (2018), Ransing et al. (2017) [13] [20].

In the present study, Table 1 and Figure 4 also show that the mean plateletcrit of both the study group and control group were within normal range. The mean plateletcrit of study subjects was no significantly higher than controls.

\section{Conclusion}

After analyzing the results of the study, it can be concluded that patients with a generalized anxiety disorder may have more future risk of thrombosis due to a 
significantly higher level of mean platelet volume, a higher level of platelet distribution width and plateletcrit than healthy adults.

\section{Acknowledgements}

The authors acknowledge the Department of Laboratory Medicine, Dhaka Medical College, Dhaka, for their kind cooperation.

\section{Conflicts of Interest}

The authors declare no conflicts of interest regarding the publication of this paper.

\section{References}

[1] Sansone, R.A. and Sansone, L.A. (2010) Psychiatric Disorders: A Global Look at Facts and Figures. Psychiatry, 7, 16-19.

[2] Islam, A. and Biswas, T. (2015) Mental Health and the Health System in Bangladesh: Situation Analysis of a Neglected Domain. American Journal of Psychiatry and Neuroscience, 3, 57-62. https://doi.org/10.11648/j.ajpn.20150304.11

[3] Markovitz, J.H. and Matthews, K.A. (1991) Platelets and Coronary Heart Disease: Potential Psychophysiologic Mechanisms. Psychosomatic Medicine, 53, 643-668. https://doi.org/10.1097/00006842-199111000-00006

[4] Moffitt, T.E., Caspi, A., Taylor, A., Kokaua, J., Milne, B.J., Polanczyk, G. and Poulton, R. (2010) How Common Are Common Mental Disorders? Evidence that Lifetime Prevalence Rates Are Doubled by Prospective versus Retrospective Ascertainment. Psychological Medicine, 40, 899-909. https://doi.org/10.1017/S0033291709991036

[5] Stein, M.B. and Sareen, J. (2015) Clinical Practice. Generalized Anxiety Disorder. New England Journal of Medicine, 373, 2059-2068. https://doi.org/10.1056/NEJMcp1502514

[6] Hou, Y., Naadiya, C., Wang, Y., Gallant, R.C., Marshall, A. and Ni, H. (2015) Platelets in Hemostasis and Thrombosis: Novel Mechanism of Fibrinogen-Independent Platelet Aggregation and Fibronectin-Mediated Protein Wave of Hemostasis. The Journal of Biomedical Research, 29, 437-444.

[7] Camacho, A. and Dimsdale, J.E. (2000) Platelets and Psychiatry: Lessons Learned from Old and New Studies. Psychosomatic Medicine, 62, 326-336. https://doi.org/10.1097/00006842-200005000-00006

[8] Budak, U.Y., Polat, M. and Huysal, K. (2016) The Use of Platelet Indices, Plateletcrit, Mean Platelet Volume and Platelet Distribution Width in Emergency Non-Traumatic Abdominal Surgery: A Systemic Review. Biochemia Medica, 26, 178-193. https://doi.org/10.11613/BM.2016.020

[9] Yilmaz, M., Delibas, I.B., Isaoglu, U., Ingee, M., Borekei, B.I. and Ulug, P. (2015) Relationship between Mean Platelet Volume and Recurrent Miscarriage: A Preliminary Study. Archives of Medical Science, 11, 989-993.

[10] Kamath, S., Blann, A.D. and Lip, G.Y.H. (2001) Platelet Activation: Assessment and Quantification. European Heart Journal, 22, 1561-1571.

https://doi.org/10.1053/euhj.2000.2515

[11] Zuberi, B.F., Akhter, N. and Afsar, S. (2008) Comparison of Mean Platelet Volume in Patients with Diabetes Mellitus, Impaired Fasting Glucose and Non-Diabetic Subjects. Singapore Medical Journal, 49, 114-116. 
[12] Kokacya, M.H., Copoglu, U.S., Kivrak, Y., Ari, M., Sahpolat, M. and Ulutas, K.T. (2015) Increased Mean Platelet Volume in Patients with Panic Disorder. Neuropsychiatric Disease and Treatment, 11, 2629-2633. https://doi.org/10.2147/NDT.S94147

[13] Almis, B.H. and Aksoy, I. (2018) Mean Platelet Volume Levels in Patients with Generalized Anxiety Disorder. Psychiatry and Clinical Psychopharmacology, 28, 43-47. https://doi.org/10.1080/24750573.2017.1385210

[14] Durmaz, T., Ozdemir, O., Keles, T., Bayram, N.A., Akcay, M., Yeter, E., Ayhan, H. and Bozkurt, E. (2009) Platelets and Sympathetic Activity in MI. Turkey Journal of Medical Science, 39, 259-265.

[15] Vizioli, L., Muscari, S. and Muscari, A. (2009) The Relationship of Mean Platelet Volume with the Risk and Prognosis of Cardiovascular Diseases. International Journal of Clinical Practice, 63, 1509-1515. https://doi.org/10.1111/j.1742-1241.2009.02070.x

[16] Asoglu, M., Aslan, M., Imre, O., Kivrak, Y., Akil, O., Savik, E., Buyukaslan, H., Fedal, U. and Altindag, A. (2016) Mean Trombosit Volume and Red Cell Distribution Width Levels in Initial Evaluation of Panic Disorder. Neuropsychiatric Disease and Treatment, 12, 2435-2438. https://doi.org/10.2147/NDT.S111108

[17] Bondade, S., Supriya Seema, S.M. and Shivakumar, B.K. (2018) Mean Platelet Volume in Depression and Anxiety Disorder-A Hospital-Based Case-Control Study. International Neuropsychiatric Disease Journal, 11, 1-8. https://doi.org/10.9734/INDJ/2018/42988

[18] Borgohain, B. and Boro, M. (2020) A Study on Mean Blood Platelet Volume Levels in Patients with Depression and Generalized Anxiety Disorder. Journal of Medical Science and Clinical Research, 8, 658-664. https://doi.org/10.18535/jmscr/v8i1.103

[19] Gul, I.G., Eryilmaz, G., Ozten, E. and Sayar, G.H. (2014) Decreased Mean Trombosit Volume in Panic Disorder. Neuropsychiatric Disease and Treatment, 10, 1665-1669. https://doi.org/10.2147/NDT.S69922

[20] Ransing, R.D., Patil, B. and Grigo, O. (2017) Mean Platelet Volume and Platelet Distribution Width Level in Patients with Panic Disorder. Journal of Neurosciences in Rural Practice, 8, 174-178. https://doi.org/10.4103/jnrp.jnrp 44516 